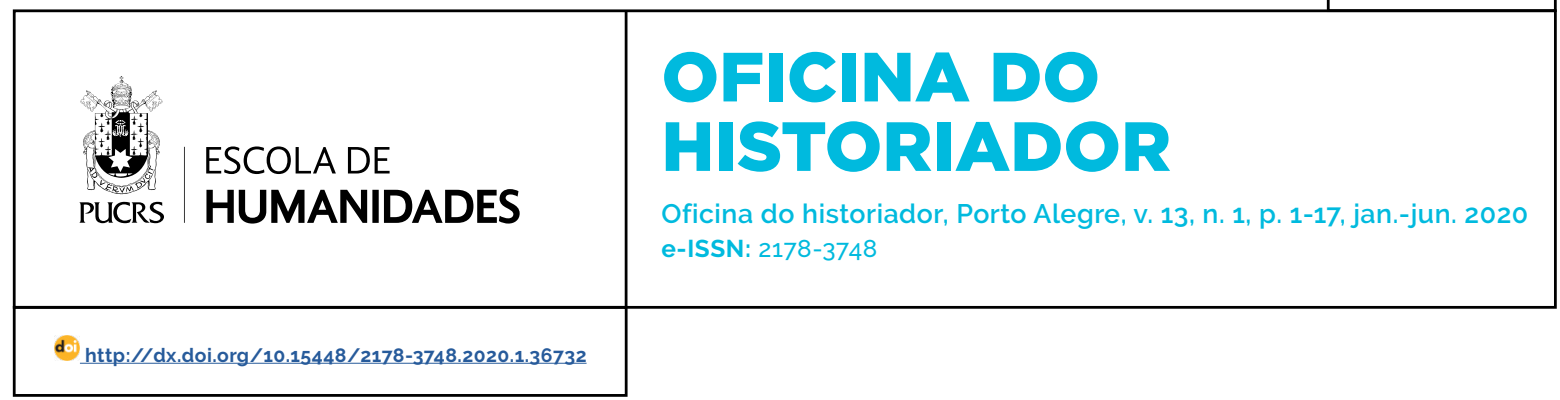

DOSSIÊ

\title{
Ensaio sobre arqueologia do periodo da borracha no Baixo Amazonas: materialidade, ontologia e patrimônio
}

\author{
Essay on Archaeology of rubber boom at Lower Amazon: materiality, ontology and heritage
}

Tiago Silva Alves Muniz ${ }^{1}$ orcid.org/0000-0002-1075-5488 tiago_samuniz@yahoo.com.br

Recebido em: 30 dez. 2019. Aprovado em: 4 mar. 2020. Publicado em: 14 jun. 2020.

\section{(c) (1)}

Artigo está licenciado sob forma de uma licença Creative Commons Atribuição 4.0 Internacional.
Resumo: Vinte e duas garrafas de grés e vidro foram encontradas por um seringueiro de Santarém em seu seringal. Localizadas próximas a um taperebá e seringueiras nativas, tais garrafas são o ponto gerador desta pesquisa, associadas ao periodo da borracha e/ou, possivelmente, à passagem de Henry Wickham pela região de Santarém. Neste ensaio apresento como esses materiais podem ser entendidos em seu contexto, a partir de perspectiva relacional e simétrica em estudos de cultura material, a fim de lançar novos dados para os estudos do período da borracha e da arqueologia histórica na Amazônia. A pesquisa ainda está em andamento, portanto, aqui apresento o contexto histórico, elaboração e discussão de hipóteses como metodologia para interpretação de dados preliminares após trabalhos de campo, entrevistas, pesquisa documental em diferentes acervos e análise de cultura material. Palavras-chave: Teoria e método em arqueologia. Cultura material. Arqueologia do capitalismo. Arqueologia histórica. Arqueologia amazônica.

Abstract:Twenty-two stoneware and glass bottles were found by rubber tapper in his rubber plantation at Santarém. Located near a taperebá and native rubber trees, these bottles are the generating point of this research, associated with the rubber boom and / or, possibly, with Henry Wickham's passage through the Santarem region. In this essay I present how these materials can be understood in their context from a relational and symmetrical perspective in material culture studies in order to launch new data to the studies of rubber boom and historical archeology in the Amazon. The research is still ongoing, so here I present the historical context, elaboration and discussion of hypotheses as methodology for interpretation of preliminary data after fieldwork, interviews, documentary research in different collections and analysis of material culture.

Keywords: Theory and method in archeology. Material culture. Archeology of capitalism. Historical archeology. Amazonian archeology.

\section{Introdução}

Seu João, seringueiro de Santarém, recentemente encontrou algumas garrafas conhecidas por ele como "bilhas", ou garrafas de grés, e garrafas de vidro em seu seringal próximo a um taperebá e seringueiras nativas. À época Floriano Pastore, pesquisador de química do látex e tecnologia da borracha para a Amazônia, recolheu tal material, o qual realiza a salvaguarda até hoje em seu laboratório na Universidade de Brasília. Posteriormente, Diogo Costa sugeriu que eu olhasse tal material, o qual escolhi para tema de minha tese de doutorado em andamento. Portanto, tais garrafas são o ponto gerador desta pesquisa, associadas ao período da borracha e/ou, possivelmente, à passagem de Henry Wickham pela 
região de Santarém. Neste ensaio apresento como estes materiais podem ser entendidos em seu contexto a partir de perspectiva relacional e simétrica em estudos de cultura material, a fim de lançar novos dados para os estudos do período da borracha e da arqueologia histórica na Amazônia.

\section{De aldeamentos, escravidão à "recolonização" e ocupação da Amazônia}

Este trabalho visa expandir o debate a partir da arqueologia histórica e contemporânea na região de Santarém, Pará, seus materiais arqueológicos dos séculos XVIII e XIX (MUNIZ; GOMES, 2017) e fluxos de pessoas e coisas durante a ocupação colonial no Baixo Amazonas (MUNIZ, 2019). Anteriormente, Symanski e Gomes (2012; 2015) analisaram a influência do contato expresso nas faianças encontradas no Sítio Aldeia, (Santarém, Pará), e nas informações históricas disponiveis. Tais registros apontaram para relações materializadas, onde diversos "encontros culturais" tiveram palco na região de Santarém, devido às relações entre europeus, indigenas de diversas etnias e, em menor escala, negros escravizados. Nesse contexto, se destaca como a influência indígena na região vai sendo impactada pela ação missioneira. Somada à presença de africanos escravizados no Sítio Aldeia (MUNIZ, 2019).

Ao evidenciar a presença de africanos livres e escravizados na Amazônia, Diogo Costa (2016) apresenta panorama das pesquisas em arqueologia dos africanos escravizados e livres na Amazônia, deslindando grande potencial de investigação para a diáspora africana na
Amazônia. Segundo Costa (2016):

Na região do Baixo Amazonas vamos
encontrar africanos escravizados para
a coleta de cravo, canela, noz-mosca-
da e principalmente cacau nativo no
século XVII no rio Tapajós. Entretanto,
sua concentração na área só vai ocorrer
nas plantações de cacau a partir da
segunda metade do século XVIII e nas
localidades de Santarém, Monte Alegre,
Alenquer e Óbidos (COSTA, 2016, p. 79).

Este artigo discutirá o periodo da borracha (1850-1920) na região, onde, conforme destacou Champney (1860) já destacava entre as cenas cotidianas na orla de Santarém. James Wells Champney (1860) retratou a presença de pessoas negras vestidas na orla de Santarém, executando atividades como preparo de bolota de borracha, dando banho em criança e lavando roupas (Figura 1). A presença de escravos em Santarém foi registrada por Rufino Luis Tavares (1876).

\begin{abstract}
Segundo o mais moderno recenseamento, o que me consta ter servido de base aos trabalhos estatisticos da respectiva directoria na corte, a população [de Santarém] é de 2.304 almas, sendo 1.120 indivíduos do sexo masculino e 1.184 do sexo feminino; são livres 1.837. escravos 467. A de toda comarca é orçada em 20.000 habitantes, o que me parece afastar-se muito da realidade (TAVARES, 1876, p. 12).
\end{abstract}

Vemos no desenho uma pessoa negra com uma bolota de látex na mão direita, cenas do cotidiano em segundo plano (homens pescando, mulher dando banho em criança e outra mulher lavando roupa) e a Igreja Matriz de Santarém ao fundo. 
Figura 1 - "Fazendo borracha" de James Wells Champney

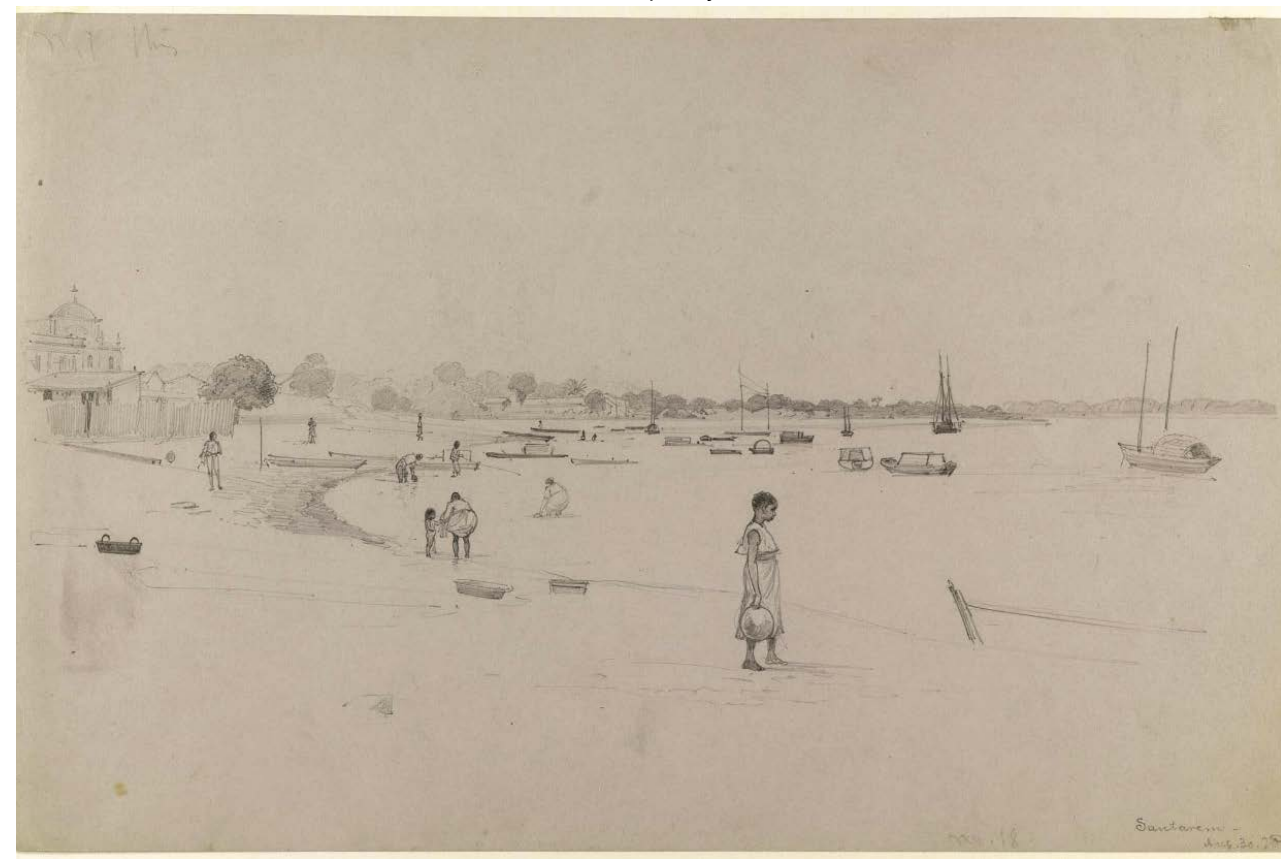

Fonte: Champney (1860).

A noção de isolamento na floresta precisa ser ressalvada, uma vez que a região era repleta de indígenas tanto tupis quanto tapuya. Dada a proximidade da região com Parintins, Condreau (1897) menciona que as estradas de caucho eram vias de fluxo de indígenas de forma pacífica na região.

Os Parintintins passam todos os anos, ao que parece, pelas estradas de caucho dos povoados do Crepori, do Caderiri e também, ao que parece, do Tapajós. Eles vão e não fazem mal a ninguém (CONDREAU, 1897, p. 21, tradução nossa).2

O componente indigena verificado a seguir, na Figura 2, para a região desde o Médio e Baixo Amazonas ao Alto Tapajós foi alvo de ação jesuitica através de instalação de missões religiosas na região, tal como a Missão Santo Inácio de Loyola, que segundo Cohen (2011, p. 13); em 1737, dada atuação do Padre Jesuita José Lopes, trouxe indigenas tupinambaranas (vindos de Parintins) e mais outros 500 de etnia(s) não mencionada(s). Nas duas décadas seguintes há a chegada de mais indígenas de outras etnias para serem ali aldeados. Essa localidade viria, em 1758, a ser elevada à categoria de vila, passando a ser conhecida como Boim, dada atuação de Medonça Furtado, que subiu e desceu o rio Tapajós, fundando, naquele ano, em 27 de fevereiro, a Vila de Monte Alegre; em 6 de março, a Vila de Alter-do-chão; em 9 de março, a Vila de Boim; em 10 de março, a Vila de Pinhel; e por último, em 14 de março, funda a Vila de Santarém.

A expedição de Mendonça Furtado demonstra a proximidade e a mobilidade entre as cinco vilas supracitadas durante o século XVIII, que atravessou o Amazonas saindo de Monte Alegre, passando por diversas localidades no Baixo Tapajós, na qual fora até o Pinhel, e voltou para Santarém em viagem de ofício para criação das vilas, tudo isso em apenas 15 dias. Tal evento propicia a reflexão sobre a comunicação entre as localidades para além da rotina de catequese rudimentar de atividades missionárias em aldeamentos, que teve com a aplicação do Diretório dos Índios (1757) a promoção da miscigenação étnica, onde, nessa nova conjuntura, os "índios cristãos" tornaram-se interlocutores entre a elite colonial diminuta e população indigena confinada (ARENZ, 2015, p. 30).

2 Do original: Les Parintintins passent tous les ans, parait-il, par les estradas de caoutchouc eles éivilisés du Crépory, elu Caderiry, et aussi, parait-il, du Tapajoz. Ils vont, ne faisant ele mal à personne. 
Figura 2 - "A Antiga Propagação e as Peregrinações Aparentes dos Tupis". Destaque para a Amazônia, onde o fluxo em vermelho aponta, desde a região da atual Parintins, passando pelo baixo Tapajós, na região da vila de Boim, até o Alto Tapajós e demais localidades em direção ao Brasil Central.

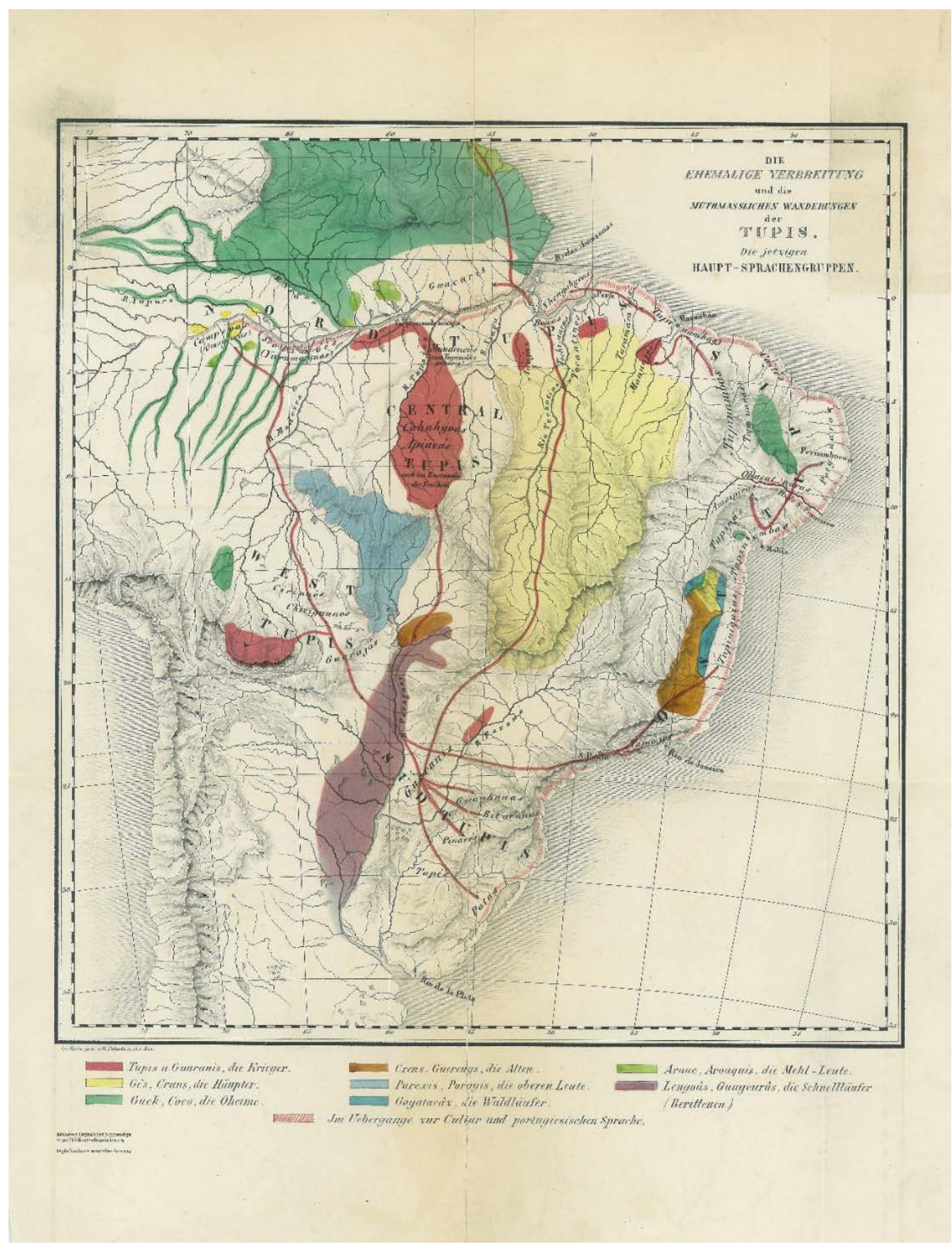

Fonte: (MARTIUS, 1867).

A presença histórica de seringueiros foi registrada ao longo do rio Tapajós por Condreau (1897), conforme aponta a Figura 3. À medida que a economia da borracha aumentava na área, comerciantes e trabalhadores se estabeleceram ao longo do rio Tapajós. Em 1879, devido à estação seca no nordeste brasileiro, muitas pessoas migraram para a Amazônia para trabalhar como seringueiros. Além disso, alguns comerciantes judeus que vieram do Marrocos desempenharam um papel importante no sistema de comércio de borracha da Amazônia conhecido como "aviamento" (WEINSTEIN, 1983; BLAY, 2008). 
Figura 3 - Extração de informações sociais sobre ocupações de seringueiros no mapa histórico do rio Tapajós

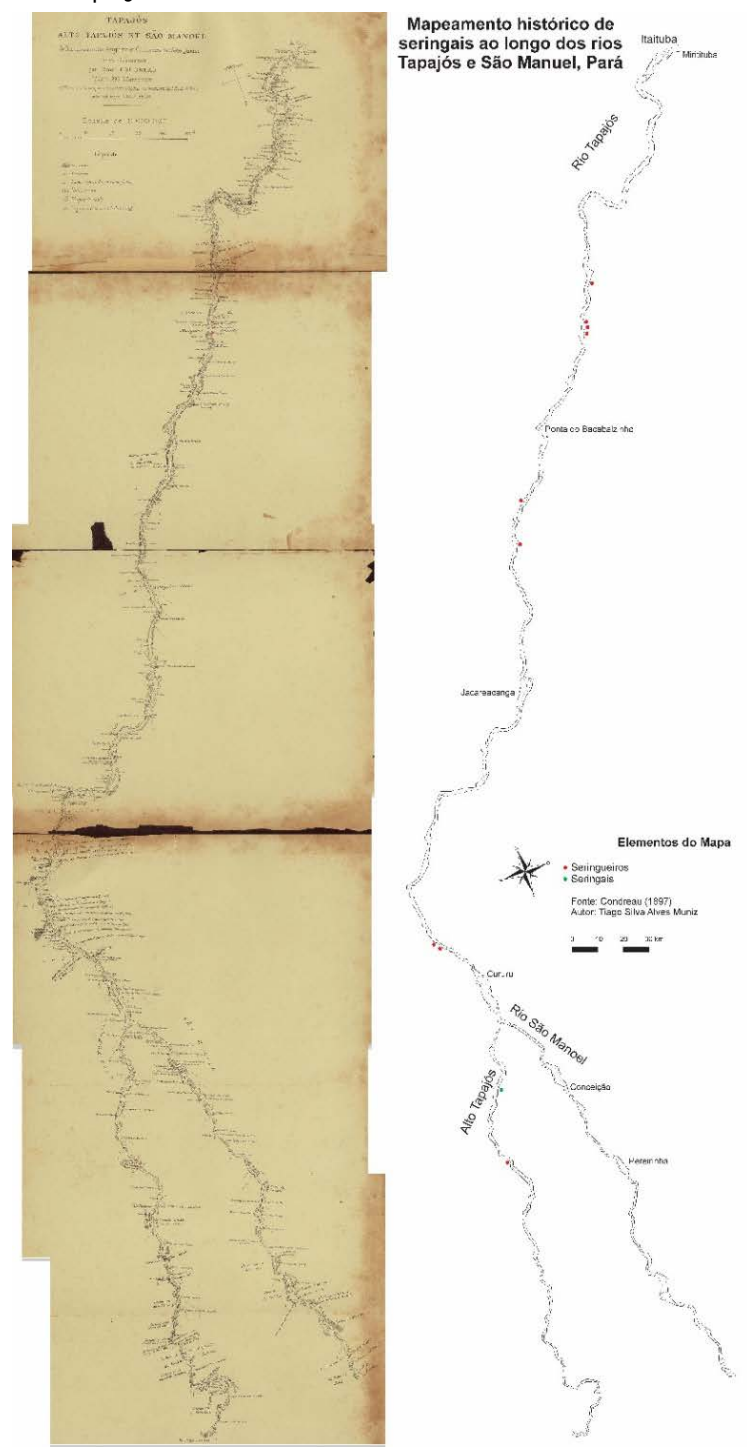

Fonte: Mapa elaborado pelo autor a partir de dados de Condreau (1897).

A historiografia da borracha retratou os seringueiros como homens solitários dentro da "solidão na selva" e a Floresta Amazônica como um "deserto verde". Mas esse discurso segue a ideia de vazios demográficos a serem cumpridos pelo desenvolvimento ocidental (ROOSEVELT, 1914), no início pela política de Getúlio Vargas para a Amazônia na década de 1940 (BRITO, 2018) e, por último, pela ditadura militar brasileira, 19641985, devido ao seu desejo de ocupar o território amazônico e "recolonizá-lo" (CESCO; LIMA, 2018).

Somente nas últimas duas décadas, foi discutido o papel das mulheres durante o boom da borracha (WOLFF, 1999; LAGE, 2010; ALVES et al., 2018; BRITO, 2018). Muitos povos indígenas também trabalharam como seringueiros e foram explorados em muitos sentidos, o que também levou a um processo de recolonização na Amazônia sem lei e ética para com os povos indigenas (CEMIN, 2017). Como mostram os mapas históricos e os materiais arqueológicos corroboram, houve uma ocupação massiva de povos indigenas na Amazônia. Portanto, não era um vazio demográfico, tornou-se um território em disputa. As histórias de seus povos foram silenciosamente esquecidas e trocadas por narrativas de selvageria e/ou discursos de solidão sobre aqueles que migraram para lá.

\section{Arqueologia, ontologia e materiais associados ao período da borracha}

Através da influência indígena, atividade missioneira, chegada de comerciantes e ainda, a presença de africanos escravizados (e fugidos), os viajantes que passaram pela região do Baixo Amazonas relataram modos de vida, as transições sociais e econômicas que tiveram ali espaço. Sem dúvida, a maior transformação foi devido ao crescimento da economia gomífera, alvo do interesse estrangeiro na região, seja na produção local ou pelo estabelecimento e passagem de Henry Wickham pela região de Santarém.

Henry Wickham foi financiado pelo governo britânico e acordou pagamento de 10 libras por cada 100 sementes de seringueira enviada. Destarte, em 1876 recebeu o pagamento pela venda de 70 mil sementes, vendidas em Kew's Garden, Royal Botanical British Garden. Suas coletas foram realizadas em Boim (Santarém, Pará), que possuia destaque no comércio de sementes de seringueira. O material, que foi o ponto gerador desta pesquisa de doutorado foram garrafas de bebida encontradas em Boim (Santarém, Pará). Vinte e duas garrafas foram encontradas em Boim por um seringueiro, interlocutor desta pesquisa. Havendo entre elas garrafas de champagne, cerveja e gin (Figura 4). Entre as garrafas de gin - de grés -, destaca uma inscrição: "Wynand Fockink Amsterdan". 
Figuras 4 - (esquerda) Algumas das garrafas de bebidas encontras em Boim; (direita) Marca de fabricante "Wynand Fockink Amsterdan"
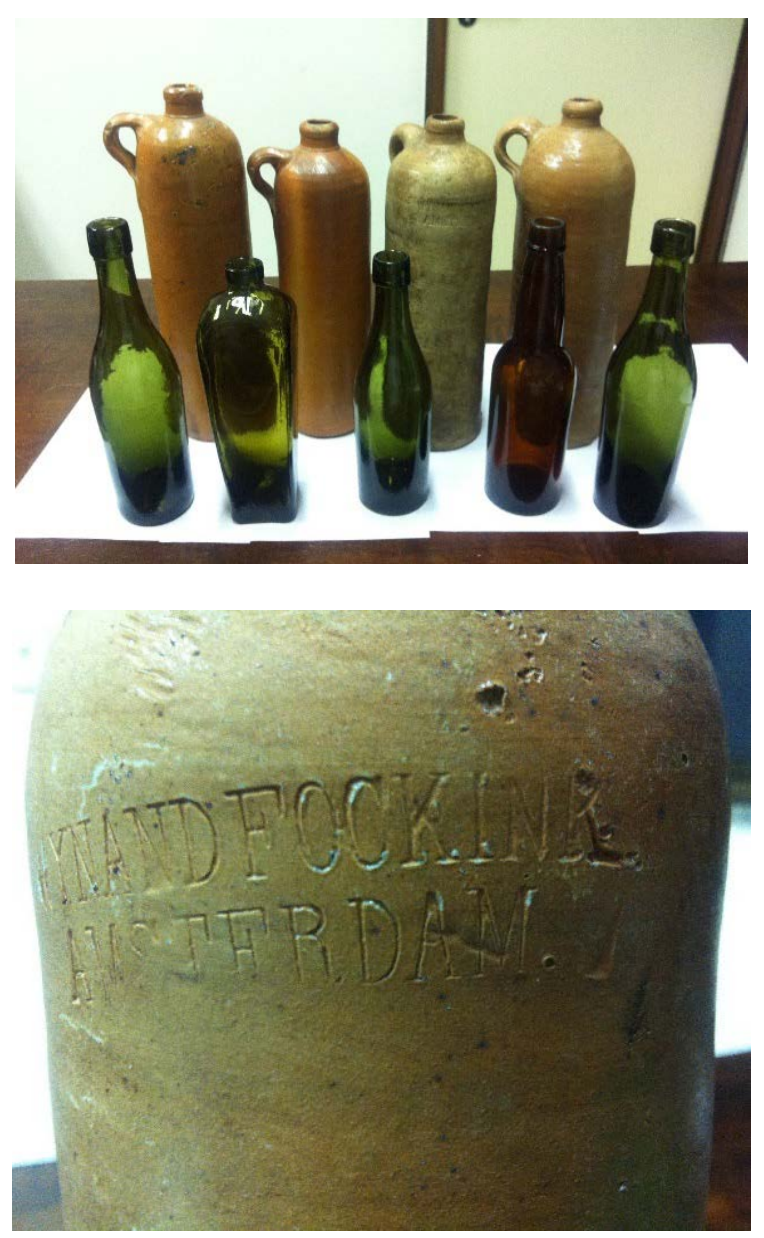

Fonte: Floriano Pastore Jr. (2017).

O impacto da descoberta do látex de Hevea brasiliensis, a seringueira, foi enorme devido ao seu alto potencial elástico e econômico que transformando o mundo e modernizando-o com os adventos dos pneus de carros e avião configurando, em grande parte, o que chamamos hoje de "vida moderna" para o século XX. Se ainda não fomos modernos, conforme afirma Latour (1994), ou ainda, se nem fomos humanos, segundo Haraway (2015), é importante destacar que foram a borracha e o feito de Wickham, elementos centrais para refletir o que consideramos, hoje, um periodo chamado antropoceno ou capitaloceno (GANE; HARAWAY, 2015). Assim, estudar a materialidade e o patrimônio associados ao período da borracha é investigar uma arqueologia do capitalismo ou da modernidade. De tal modo, a materialidade do periodo da borracha pode revelar, a partir de narrativas locais, de emaranhados de relações e materiais que produziram tantas relações, etnogênese, conflitos e riqueza na região.

Partindo de prisma relacional sobre fruir com o ambiente, conforme entendido por Tim Ingold (2000), a abordagem dissolve fronteiras para assumir discursos silenciados nos materiais. Tratase de romper o silêncio e a noção inerte das coisas, ou compreender a ontologia dos objetos (OLSEN, 2010). De tal modo, tal abordagem advoga que ser-se humano é viver com/entre coisas (VALE, 2015). Nesse sentido, destaco a forma como Tim Ingold (2000) concebe o processo de fazer coisas em seu aspecto relacional, simétrico.

O relato ortodoxo ocidental, [...] estende a ideia de fazer do domínio das coisas inanimadas para o dos seres animados. Quero sugerir, pelo contrário, que a ideia de crescimento possa ser estendida na direção inversa, do animado ao inanimado. O que chamamos de "coisas" também cresce. Na prática, há mais na fabricação de artefatos do que a transcrição mecânica de um 'design' ou plano, concebido através de um processo intelectual da razão, para uma substância inerte. Pois, [...] as formas de artefatos não são fornecidas com antecedência, mas são geradas no e através do movimento prático de um ou mais agentes habilidosos em seu envolvimento ativo e sensorial com o material. Ou seja, eles emergem - como as formas de seres vivos - dentro dos contextos relacionais do envolvimento mútuo das pessoas e de seus ambientes. Portanto, na análise final, não há distinção absoluta entre fazer e crescer. já que o que chamamos de "fazer coisas" não é, na realidade, um processo de transcrição, mas um processo de crescimento. (INGOLD, 2000, p. 87-88, tradução nossa). ${ }^{3}$

\footnotetext{
3 Do original: The orthodox Western account, [...] extends the idea of making from the domain of inanimate things to that of animate beings. I want to suggest, quite to the contrary, that the idea of growing might be extended in the reverse direction, from the animate to the inanimate. What we call 'things', too, are grown. In practice, there is more to the manufacture of artefacts than the mechanical transcription of a design or plan, devised through an intellectual process of reason, onto an inert substance. [...] as the forms of artefacts are not given in advance but are rather generated in and through the practical movement of one or more skilled agents in their active, sensuous engagement with the material. That is to say, they emerge - like the forms of living beings - within the relational contexts of the mutual involvement of people and their environments. Thus there is, in the final analysis, no absolute distinction between making and growing. since what we call 'making things' is, in reality, not a process of transcription at all but a process of growth.
} 
Portanto, o que podemos falar a partir da materialidade? E como nosso posicionamento pode colaborar com as comunidades no contexto de nossas pesquisas? Os arqueólogos Shanks e Tilley (1988) afirmam que a arqueologia é uma ação sociopolítica no presente, enquanto McGuire (2008) nos lembra que todo conhecimento é político. Assim, toda forma de arqueologia é política e não existe um caminho do meio, uma possivel neutralidade nos discursos sobre o passado. Castañeda (2008) pontua que o observador, a pesquisa e o campo se entrelaçam e a visão de arqueologia como ação política desafia os mecanismos de opressão e produção de desigualdades para emancipação. Desse modo, refletir a partir dos objetos e das coisas para pensar as transformações sociais e econômicas pode reverberar em uma práxis relacional de correspondência, coerência e contexto voltados para as consequências que ainda impactam o bom viver no Baixo Amazonas.

Por fim, penso que a partir de tal abordagem interpretativa e de abordagem contextual cada vez mais minuciosa, a arqueologia pode compreender como as interações se deram no passado e podem visibilizar as pessoas, trajetórias, seus materiais e fluxos, assim como identidades para contribuir com a construção de uma disciplina cada vez mais analitica, semântica e menos arqueográfica, onde o impacto da etnografia das coisas e lugares não fiquem restritos ao academicismo e possam dialogar com as compreensões que as comunidades no presente têm acerca de seu próprio passado, cabendo ao arqueólogo o papel de mediação entre as coisas e as pessoas; o objeto e o pesquisador para materialização de significados e dissolução de fronteiras.

Nesse sentido simétrico, Ingold (2013) discorda do arqueólogo Colin Renfrew ao abordar o engajamento material a partir da experiência das potencialidades do material, propondo uma visão da coisa para o humano, e não do humano para coisa. Ingold (2013) destaca que o aspecto relacional entre "criador e criatura" e as relações que acontecem em um mundo de materiais, não devem ser encaradas como propriedades ou atributos dos materiais, e sim como histórias.

A alegação, portanto, de que uma escultura é boa porque revela a 'pedregosidade' da pedra não pode ser justificada com base nas propriedades que podem ser objetivamente conhecidas. Simplesmente revela nossas preferências pessoais sobre as qualidades que gostamos de ver nela. Agora, podemos claramente ter essas preferências em relação aos materiais que usamos para fazer as coisas. Também é verdade que esses materiais podem ser submetidos a uma bateria de testes para medir propriedades como densidade, elasticidade, resistência à tração, condutividade térmica e assim por diante. Para um engenheiro que se propõe a projetar uma estrutura e decidir quais materiais usar, essas medições - que podem ser tão precisas e objetivas quanto a ciência e a instrumentação atuais permitirem serão de importância crítica. No entanto, o conhecimento que eles fornecem não tem nenhum ponto de comparação com o de, por exemplo, o pedreiro, o ferreiro, o oleiro ou o carpinteiro, uma vez que provêm da experiência de uma vida inteira trabalhando com o material. Trata-se de conhecimento nascido da percepção sensorial e do engajamento prático, não da mente para o mundo material - para lembrar a "teoria do engajamento material" de Renfrew (2001) - mas do profissional especializado que participa de um mundo de materiais (INGOLD, 2013, p. 35, tradução nossa). ${ }^{4}$

Desse modo, exponho a seguir que a abordagem simétrica é um caminho para definitiva conciliação entre coisas, humanos, não humanos, arqueologia e antropologia. A noção de cultura de Franz Boas

\footnotetext{
4 Do original: La afirmación, entonces, de que una escultura es buena porque pone de manifiesto la pedregosidad de la piedra no puede ser justificada sobre la base de las propriedades que pueden ser objetivamente conocidas. Simplemente revela nuestras preferencias personales sobre las cualidades que nos gusta ver en ella. Ahora bien, claramente podemos tener dichas preferencias en relación a los materiales que utilizamos para hacer cosas. También es cierto que estos materiales pueden ser sometidos a una bateria de pruebas con el fin de medir propiedades como densidad, elasticidad, resistencia a la tracción, conductividad térmica y así sucesivamente. Para que un ingeniero que se propone diseñar una estructura y decidir qué materiales utilizar, tales medidas - que pueden ser tan precisas y objetivas como la ciencia actual y la instrumentación lo permitan - serán de una importancia crítica. Sin embargo, el conocimiento que ellas aportan no tiene punto de comparación con el de, por ejemplo, el albañil, el herrero, el alfarero o el carpintero, pues en ellos provienen de la experiencia de toda una vida de trabajo con el material. Este es un conocimiento nacido de la percepción sensorial y el compromiso práctico, no de la mente con el mundo material - para recordar la "teoria del compromiso material" de Renfrew (2001) - sino del profesional especializado participando en un mundo de materiales. (INGOLD, 2013).
} 
(1938, p. 159) em sua abordagem totalizante inclui os aspectos ambientais, corporais, mentais, sociais, culturais e os produtos de tais interações. Franz Boas foi singular ao se posicionar contra o evolucionismo e a abordagem de determinismo biológico na noção de cultura, assim como ao se posicionar contra a noção de raça ao passo que seus estudos fundaram a chamada Antropologia Quatro Campos, unindo antropologia cultural (social), antropologia física (biológica), linguística e arqueologia. Nesse sentido, a definição "boasiana" de cultura reflete uma abordagem totalizante/sistêmica dos elementos culturais, escrita ainda na década de 1930.

Cultura pode ser definida como a totalidade das reações e atividades mentais e físicas que caracterizam o comportamento dos individuos que compõem um grupo social coletiva e individualmente em relação ao seu ambiente natural, a outros grupos, aos membros do próprio grupo e de cada individuo para si mesmo. Isso também inclui os produtos dessas atividades e seu papel na vida dos grupos (BOAS, 1938, p. 159, tradução nossa). ${ }^{5}$

Destarte, em minha pesquisa, divergindo da abordagem meramente arqueográfica, voltada para descrição de materiais, buscarei refletir sobre o contexto histórico dos vestígios encontrados e quais são as percepções das narrativas promovidas pelos moradores da vila de Boim, sob o olhar da fluidez dos materiais e sua relação dos indivíduos, grupos sociais, história, memória, objetos e entorno. A seguir, vejamos neste ensaio quais seriam as hipóteses para interpretação de tais materiais.

\section{Hipótese 1: As garrafas são de Henry Wickham?}

De início, os interlocutores desta pesquisa associaram as garrafas de origem holandesa à passagem de Herny Wickham pela região, sendo pensadas como de posse do inglês. Nesse sentido, foi explicitado aos envolvidos, com a pesquisa, que a arqueologia possui seus limites, sendo tal tipo de afirmação precipitada dada ausência de informações contextuais. Além disso, tal fato parece improvável dada a característica altamente comercial desse tipo de produto (garrafas de grés), onde, as inscrições observadas nas garrafas não se trata de uma marca de família ou marca de posse, e sim de uma marca de fabricante. Tais garrafas, são achados comumente revelados pela arqueologia histórica em todo país, produzidas desde meados do século XVII.

No século XVII, quando os navios da VOC trouxeram ervas, especiarias e açúcar para Amsterdã, os destiladores começaram a destilar licores em larga escala. A razão pela qual a indústria de licor de Amsterdã estava se tornando tão importante era que a cidade se tornara muito próspera e que o licor. ao contrário da cerveja e da genebra, era uma bebida cara que somente os ricos podiam se dar ao luxo de beber regularmente. Quando em 1724 Wynand Fockink adquiriu a destilaria e o bar no Pijlsteeg, que remonta a 1679, Amsterdã ainda era uma cidade rica e próspera, com uma próspera indústria de licores. Em 1778, Wynand Fockink morreu e deixou a empresa para seu único herdeiro sobrevivente, sua filha Maria. Depois da morte de seu pai, Maria continuou a destilaria junto com o destilador Dentzel. O negócio estava florescendo e, através das netas de Maria, veio nas mãos da familia Schmitz. Até a aquisição de Lucas Bols em 1954, a empresa era administrada por descendentes de Wynand Fockink. Sob Wynand Fockink e seus descendentes, a destilaria de licores se tornou uma das maiores destilarias holandesas. No final do século XVIII, a empresa possuia seis grandes instalações no Oudezijds Voorburgwal e outras seis no Pijlsteeg. Na primeira década do século XIX, a empresa também se expandiu pela exportação. Nessa época, Wynand Fockink possuía casas comerciais em Berlim, Viena, Bruxelas e Paris. Entre 1815 e 1860, a França foi um dos maiores clientes de licor. Naqueles dias uma passagem foi construida entre o Damstraat e o Pijlsteeg a fim aumentar a visibilidade do proeflokaal (taberna de degustação) atual de Wynand Fockink. Por volta de 1870, Wynand Fockink tinha 80 funcionários, operava cinco alambiques e usava uma máquina a vapor de 30 cavalos de potência. Na mesma época, a exportação para os EUA começou a crescer e, em 1920, a Wynand Fockink

\footnotetext{
5 Do original: Culture may be defined as the totality of the mental and physical reactions and activities that characterize the behavior of the individuals composing a social group collectively and individually in relation to their natural environment, to other groups, to members of the group itself and of each individual to himself. It also includes the products of these activities and their role in the life of the groups.
} 


\section{se tornou uma empresa pública, até aquele ano sempre fora uma empresa familiar" (WYNAND FOCKINK, 2017. grifo nosso, tradução nossa). ${ }^{6}$}

Sobre os materiais de grés, Rafael de Abreu Souza (2013) aborda que, em geral, estes são importados da Inglaterra e Holanda, comumente associados à garrafas, garrafões e botijas enquanto contentores de líquidos, alimentos em conserva e tinteiros (BRANCANTE, 1981 apud SOUZA, 2013, p. 44). É importante ressaltar ainda, que as bebidas de gin, ou genebra, seriam itens de alto valor aquisitivo à época. Assim, é necessário incorporar variáveis como as socioeconômicas ao abordar relações entre os materiais arqueológicos encontrados e os individuos. Para tal, a arqueologia histórica faz uso metodológico da Escala de Miller (1980).

A escala econômica de Miller (1980), ou "CC Index", é baseada em pesquisas de listas de preços de fabricantes entre o final do século XVIII e 1880. Essa abordagem é utilizada com frequência para verificar o grau de investimento por parte dos ocupantes de um sítio. Miller (1980) classificou os itens em quatro niveis revelando distintas taxas de valor aquisitivo sendo os níveis 1 e 2 relativos aos itens mais caros e os níveis 3 e 4 aos mais baratos. Tais garrafas seriam itens caros à época.

\section{Hipótese 2: As garrafas são forma de} pagamento pelas sementes de borracha?

O alto valor de compra de tais garrafas de bebidas pode ter influenciado de diferentes formas a aquisição das mesmas e a deposição na vila de Boim. Ao abandonarmos a ideia reducionista que tais itens de fabrico europeu seriam de posse de Henry Wickham, caminhamos para uma reflexão apontando para essas garrafas como itens de troca adquiridas como possivel pagamento pela prestação de serviços de retirada de sementes da floresta. Hipótese em aberto.

Outra pergunta surge: o que as 22 garrafas de bebidas estariam fazendo enterradas no meio da floresta? Não tive acesso a fotos do momento em que elas foram encontradas, apenas a algumas garrafas já coletadas e higienizadas. A primeira tentativa de responder a tal questão foi que seriam de posse de Henry Wickham, hipótese já descartada. A segunda é que seriam fruto de pagamento pela prestação de serviços de retirada de sementes, ainda assim, por que estariam todas enterradas juntas? Sobre informações de cunho contextual, tive acesso apenas ao relato sobre a existência de uma tampa que cobria as garrafas no solo, curiosamente descrita como "tampa de vidro". De início, por associação a padrões de enterramento pré-colonial na Amazônia, imaginei que a tampa mencionada poderia ser de cerâmica. Mas o interlocutor foi bastante claro quanto à composição do material. Pensei na hipótese do mesmo ser a base de uma grande garrafa de vidro quebrada, utilizada para cobrir essas garrafas de bebidas.

\section{Hipótese 3: As garrafas foram utilizadas como meio de transporte para as sementes de borracha?}

A hipótese inicial de que as garrafas teriam sido enterradas e escondidas para o "contrabando" de sementes foi de início negada. Primeiro, porque as sementes de seringueira que tive contato provavelmente não entrariam em um gargalo

\footnotetext{
6 Do original: In the 17th century, when the VOC ships brought herbs, spices and sugar to Amsterdam, distillers started distilling liqueurs on a large scale. The reason that the Amsterdam liqueur industry was becoming so important was that the city had become very prosperous and that liqueur, contrary to beer and genever, was an expensive drink which only the rich could afford to drink on a regular basis. When in 1724 Wynand Fockink acquired the distillery and the bar in the Pijlsteeg dating back to 1679. Amsterdam was still a rich and prosperous city with a thriving liqueur industry. In 1778 Wynand Fockink died and left the company to his single surviving heir, his daughter Maria. After her father's death Maria continued the distillery together with distiller Dentzel. Business was flourishing and through Maria's granddaughters it came in the hands of the Schmitz family. Until the takeover by Lucas Bols in 1954, the company was managed by descendants of Wynand Fockink. Under Wynand Fockink and his descendants, the liqueur distillery became one of the largest Dutch distilleries. By the end of the 18th century the company owned six large premises on the Oudezijds Voorburgwal and another six in the Pijlsteeg. In the first decade of the 19th century the company expanded through export as well. By that time. Wynand Fockink owned trading houses in Berlin, Vienna, Brussels and Paris. Between 1815 and 1860. France was one of the largest liqueur customers. In those days a passage was constructed between the Damstraat and the Pijlsteeg in order to increase the visibility of the current Wynand Fockink proeflokaal. Around 1870 Wynand Fockink had 80 employees, operated five stills and used a steam engine of 30 horsepower. In the same era export to the USA started to grow and in 1920 Wynand Fockink turned into a publicly owned company, until that year it had always been a family owned company..
} 
devido ao seu tamanho. E, segundo, porque esta narrativa quanto à ilicitude da coleta de Wickham é questionável, uma vez que mesmo que seja considerado "o maior ato de biopirataria da humanidade" (JACKSON, 2011), provavelmente na década de 1870 não havia fiscalização em Santarém que obrigasse Wickham a reportar, ou legalizar, suas coletas. Entretanto, pelo contrário, é sabido que ele teve uma autorização para coleta no Grão-Pará.

Em outubro de 2019 fui ao British Royal Botanical Garden, Kew Gardens, e realizei pesquisa documental no acervo e herbário (Figura 5). Ao analisar materiais associados à coleção de sir Henry Wickham e Hevea brasiliensis pude notar que no material carpológico há variações consideráveis no tamanho das sementes e a presente hipótese voltou a ser um questionamento pertinente, permanecendo em aberto. Segundo Carvalho, (2017) as sementes selvagens de Hevea brasiliensis variam em (centímetros): largura 2,0 +- 0,10; espessura 2,1 +- 0,11; comprimento $2,9+-0,11$; já as clones variam entre largura 1,5 +- 0,12; espessura 1,6 +- 0,13; comprimento 2,1 +- 0,14; tais variações entre nativas e hibridas apontam variabilidade considerável, entretanto, a análise da cultura material demonstrou que os gargalos têm abertura de 2,0 a 2,1 cm. Dessa forma, testes de espectofotometria de massa devem ser realizados na tentativa de recuperar informações de paredes internas das garrafas de grés e seus potenciais usos.

Figura 5 - Documentação e material carpológico analisado no herbário de Kew Gardens, coleção de Hevea sp.

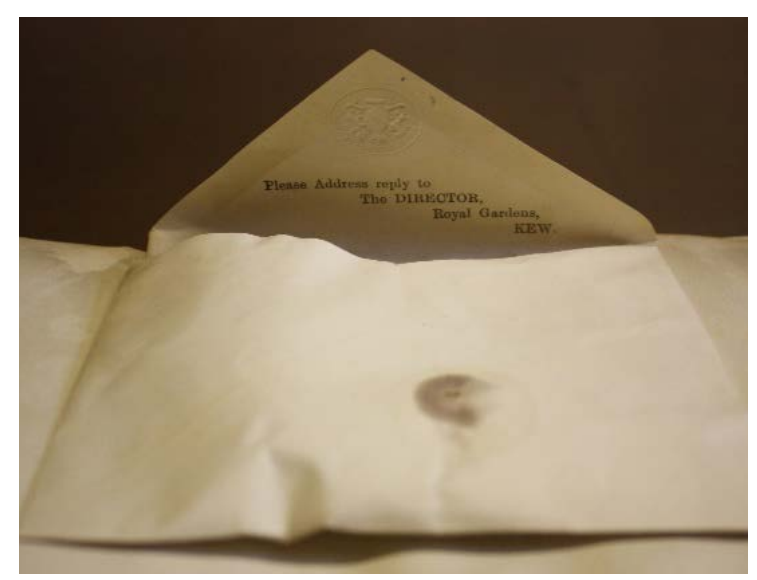

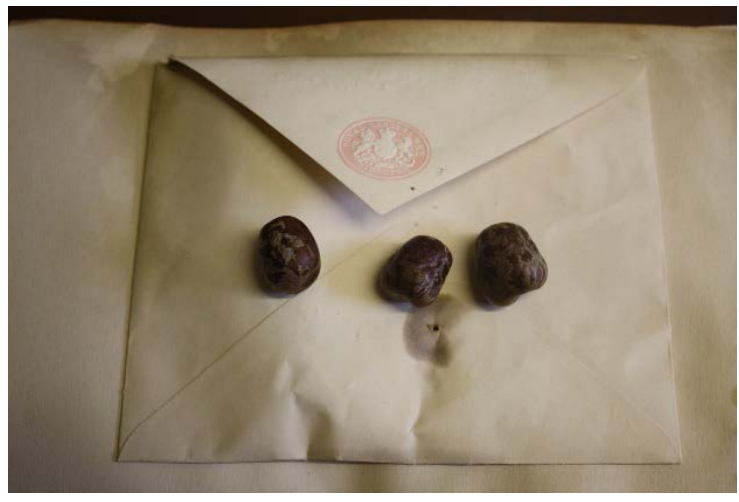

Fonte: Tiago Muniz (2019).

\section{Hipótese 4: As garrafas não seriam associadas à Wickham e outrossim reutilizadas como containers para armazenamento de líquidos?}

Em esforço interpretativo para entender a referida "tampa de vidro" que estaria cobrindo as garrafas quando o seringueiro encontrou os materiais, pensei que a referida "tampa" poderia ser a base quebrada uma garrafa de vidro grande. Portanto, tentei associar esse material de vidro ao maior diâmetro de garrafa que já tive contato em coleção de materiais arqueológicos e logo remeti às garrafas do estilo Demijohn (Figura 3). Cabe ressaltar ainda que garrafas do tipo Demijohn são encontradas na Amazônia associadas ao contexto do periodo da borracha, vide a coleção do municipio de Tartarugalzinho (Amapá), salvaguardado na Reserva Técnica do Laboratório de Arqueologia Peter Hilbert, Núcleo de Pesquisa Arqueolóica do Instituto de Pesquisas Científicas e Tecnológicas do Estado do Amapá (NUPArq/IEPA). Uma informação relevante quanto ao tipo morfofuncional dessas garrafas Demijohn é justamente o seu conteúdo líquido armazenado: produtos químicos fortes, principalmente ácidos (ODELL, 2008 apud LINDSEY, 2018). O que pode reforçar a hipótese dessas garrafas estarem associados à materialidade do período da borracha em possivel distribuição do produto em demais recipientes.

Seria esse contexto associado a uma tentativa deposicional de conter ácidos voláteis utilizados para tratamento da borracha? Nesse sentido, 
pretendo expandir a pesquisa sobre métodos de conservação do látex e quais técnicas foram implementadas na Amazônia. Há relatos históricos sobre os odores fétidos exalados nas matas durante o periodo da borracha ao se defumar a borracha, além da insalubridade e da mortandade associadas à qualidade de vida e tais condições de trabalho durante tal periodo. Destaco ainda, que durante a vivência realizada em agosto de 2017, após passar alguns dias na vila de Boim e na comunidade do Maguary em Belterra (Resex Tapajós-Arapiuns e Flona do Tapajós, respectivamente), pude constatar que nas comunidades de Belterra durante a manufatura do látex para artesanato se utiliza amônia para evitar a coagulação do leite. Nesse sentido, ressalto que a amônia é volátil e utilizada desde meados do século XIX para o tratamento de látex, entretanto, pouco se sabe sobre as técnicas de extração e tratamento de látex durante o primeiro ciclo da borracha na Amazônia (1850-1920).

Pelo conjunto dos parâmetros de disponibilidade comercial, baixo custo, facilidade de operação em campo e na indústria, proteção do coloide evitando coalescência e colapso do látex e, finalmente, de protetor biológico, a amônia se transformou no protetor universal para LBN7 em condição que já se estende desde 1853 (BLACKLEY, 1997 apud PASTORE Jr., 2017, p. 34, grifo nosso).

\section{Hipótese 5: As garrafas podem} representar a agência dos seringueiros?

Conforme supracitado, os dados para as técnicas de produção de borracha na Amazônia são praticamente inexistentes. É sabido que quem inventou a técnica de vulcanização da borracha foi Charles Goodyear (1839) e Hancock (1842) foi quem deu nome à técnica de aquecimento e adição de componentes químicos, mantendo um estado elástico e propriedades do material (HILLS, 1971, p. 4). Nesse sentido, a pesquisa aqui realizada visa investigar a seara tecnológica da produção da borracha a fim de investigar se tal procedimento seria realizado in situ.
Aqui pretendo discutir a cultura material à luz de James Deetz, que a define como "todo e qualquer segmento do mundo físico culturalmente modificado" (1996). Desse modo, busco compreender como tais gases fétidos e tóxicos se relacionam para compor as condições de trabalho às quais estavam sujeitados os seringueiros. Nesse sentido, trago uma reflexão de Vinícius de Rezende (2013) sobre as indústrias de curtume e borracha:

Para além das necessidades materiais, muitos depoentes associaram a capacidade de suportar o trabalho em curtumes e indústrias de borracha à postura viril do sujeito "[...] Realmente era duro, não era fácil não." Na seção de caleiro do Curtume Progresso, "eles só pegava mesmo esses homem forte, porque a parte do caleiro é a mais pesada que tem. [...] Então precisava de nego macho mesmo pra trabalhar." A recorrência do termo "macho" nos depoimentos delineia aspectos da "cultura masculina", que enaltece o esforço, o vigor físico e a capacidade dos homens suportarem condições de trabalho adversas (REZENDE, 2013, p. 5).

Buscarei aqui lançar olhar para a agência dos seringueiros ao suportar essa e outras condições de trabalho e a punição retratada pela historiografia do periodo da borracha. A reflexão relacional com o mundo de materiais aqui apresentada é que as impurezas de matéria orgânica adicionadas ao látex extraído visam aumentar o rendimento na produção de bolotas. O que pode corroborar os relatos sobre a dita má qualidade do látex brasileiro frente ao crescente mercado asiático à época. Seria um aspecto relacional, conforme proposta de Ingold (2000), pois possivelmente tal adição pode ter ocorrido de maneira passiva, à medida que se dava sangria das seringueiras, a dinâmica florestal em plena consonância com os interesses dos seringueiros se encarregava de acrescentar matéria orgânica aos recipientes coletores ao vento esbravejar o adensamento de folhas e galhos secos, assim como restos de insetos e outros materiais que comumente entram nos coletores de látex durante uma coleta em área de floresta. 
Hipótese 6: As garrafas eram utilizadas para transporte de água ou item de troca?

Na Figura 6, notam-se elementos da cultura material associada ao periodo da borracha, aparatos amarrados aos animais de carga e ferramentas dispostas sobre um tronco. É interessante resgatar a noção de "estradas de caucho" de Henri Condreau (1897), que esteve em Boim durante a sua expedição ao rio Tapajós. Dada a proximidade da região com Parintins, o autor menciona que tais estradas de caucho eram vias de fluxo de indigenas de forma pacifica na região, podendo essas garrafas terem sido transportadas por animais ou ainda trocadas com indigenas da região. Entretanto, tais garrafas de grés são muito pesadas, dificultando tal uso e apresentando poucas marcas em sua superficie (a ser analisado novamente).

Figura 6 - Registro do modo de acesso às "estradas de caucho"

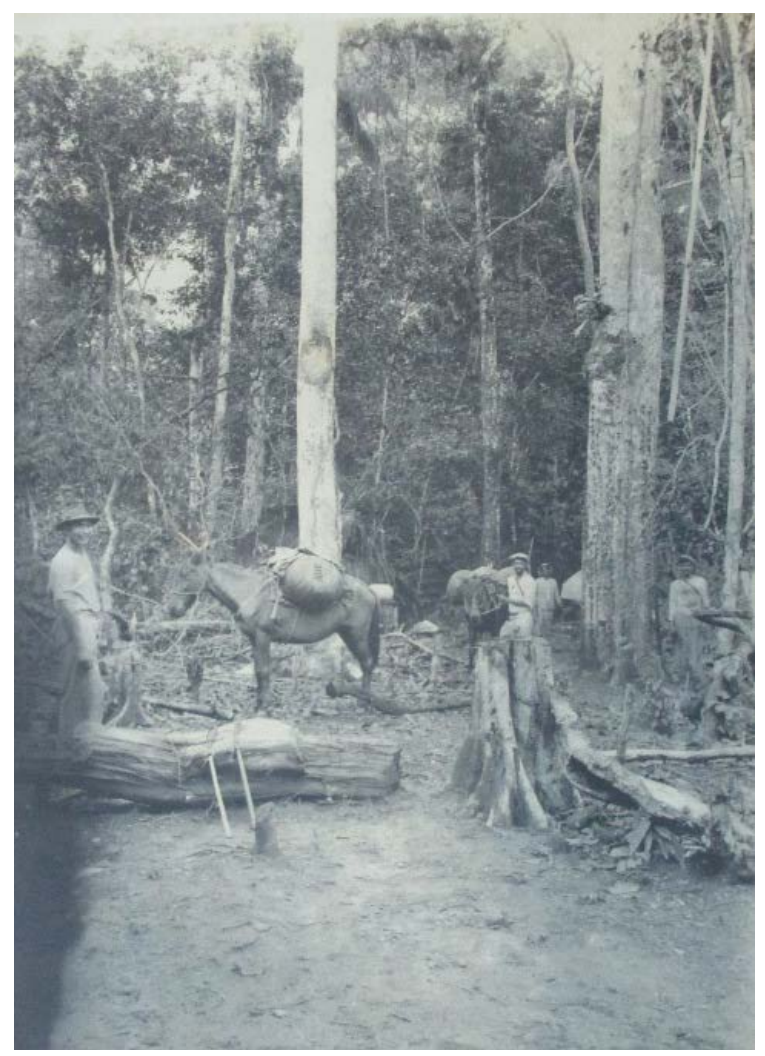

Fonte: ULE, 1908-1909.
Hipótese 7: As garrafas foram enterradas para evitar furto por transeuntes?

Na figura 7 observam-se gêneros alimentícios cultivados, bananas, milho, abacaxi e palmeiras. Refletir sobre a alimentação nesse contexto também pode ajudar a entender a participação da agência do seringueiro em um sistema extrativista de modelo caboclo versus o modelo do apogeu (OLIVEIRA FILHO, 1979). Nesse sentido, destaco, em oposição ao sistema extrativista caboclo, as figuras 8 e 9 , que retratam a participação da economia gomifera na construção de cidades amazônicas, dado apogeu do ciclo da borracha.

Figura 7 - Registro do modo de subsistência (?) na mata em arredores do seringal.

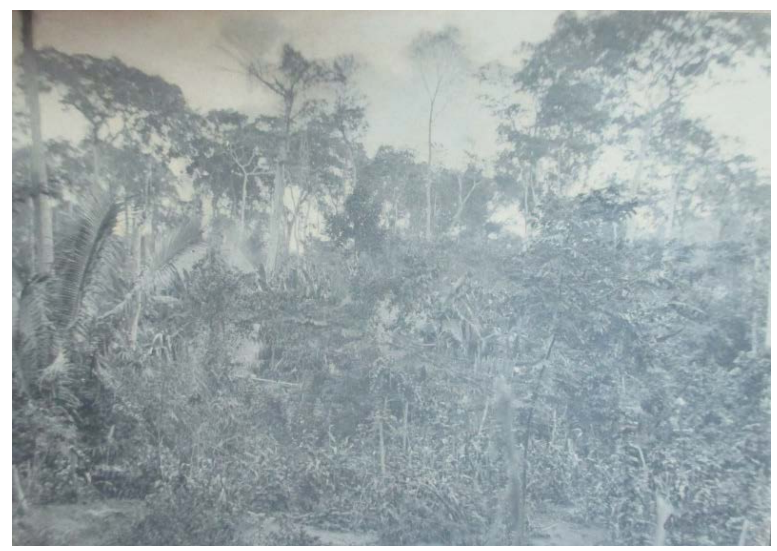

Fonte: ULE, 1908-1909.

Figura 8 - Economia gomífera na Estrada de Ferro Madeira Mamoré, Rondônia

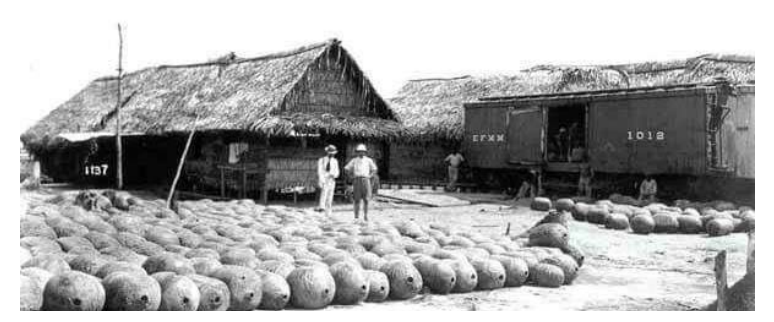

Fonte: Imagem sem proveniência. 
Figura 9 - Economia gomífera na Estrada de Ferro Madeira Mamoré, Rondônia.

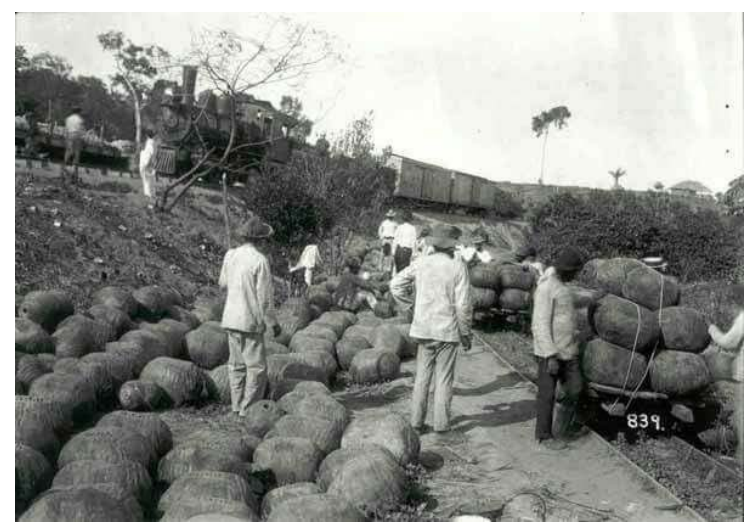

Fonte: Imagem sem proveniência.

Hipótese 8: Garrafas de vidro e cestos foram utilizados no transporte de sementes?

Outra informação relevante sobre a possivel "tampa de vidro", correlacionada por mim de modo interpretativo às garrafas de formato Demijohn é o fato dessas garrafas estarem comumente associadas a cestos de palha (Figura 10), possivelmente a melhor forma de transportar seus conteúdos ácidos. Sobre tais cestos, cabe ressaltar trecho do livro de Joe Jackson O Ladrão no Fim do Mundo - Como um inglês roubou 70 mil sementes de seringueira e acabou com o monopólio do Brasil sobre a borracha. O autor entrevistou Eden Cohen ${ }^{8}$ em 21 de outubro de 2005 ao escrever seu livro. Na entrevista, Cohen destaca uma foto que possui de um cesto tecido por sua filha. Segundo reporta Jackson (2011, p. 371): "É do mesmo modelo dos usados por Wickham e por índios e caboclos por séculos. A única diferença em relação aos cestos de Wickham é que os dele devem ter sido maiores".
Figura 10 - (esquerda) Garrafa do tipo Demijohn; (direita) Tipo de cesto associado.
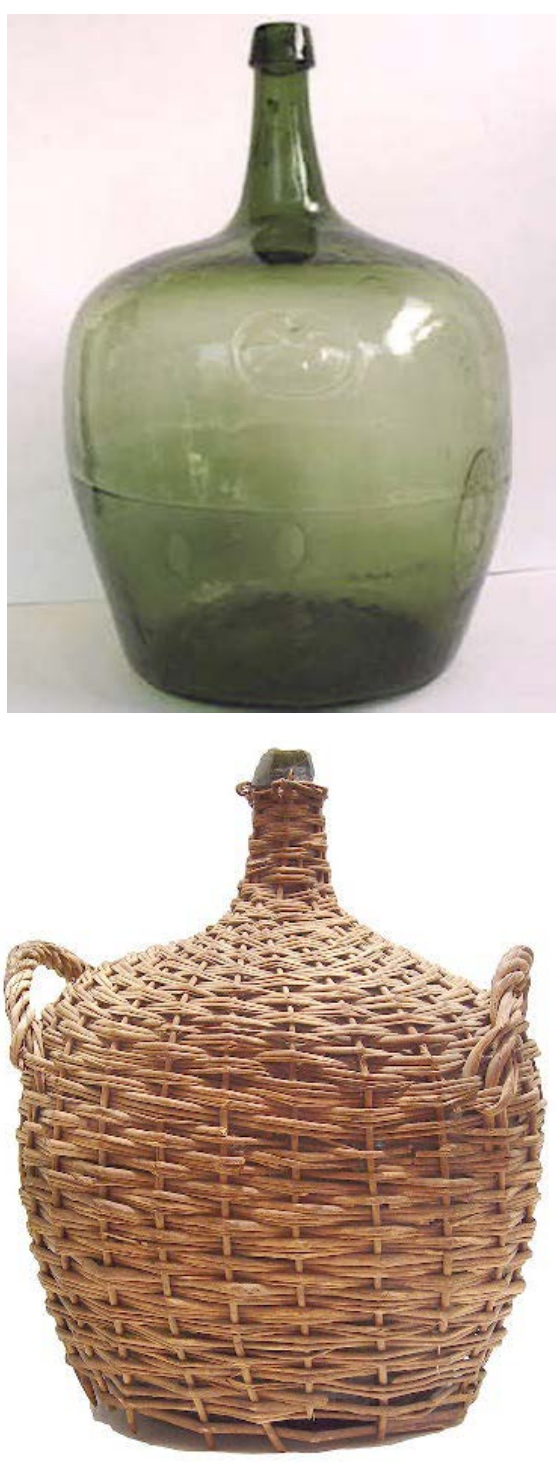

Fonte: Lindsey (2018).

\section{Hipótese 9: Os cestos de palha são os} chamados jamanxins?

Tais cestos de palha mencionados podem auxiliar a compreender mais o transporte de sementes de Hevea sp. uma vez que as garrafas de grés foram associadas como veículos de transporte das sementes, entretanto, essa hipótese parece incongruente, uma vez que a abertura do gargalo seria muito estreita para a entrada de sementes de seringueira. Ainda

\footnotetext{
8 Cohen é ilustre personalidade, nascido e criado em Boim. Estudou até a 5 . $^{\text {a }}$ série primária e além dos dois livros publicados sobre a história de Boim se destaca como poeta interiorano e trabalho para Boim e comunidades circunvizinhas.
} 
assim, cabe checar a hipótese de que há, nos arquivos de Londres, material de transporte associado às sementes de Wickham em museus, auxiliando a compreensão da cultura material deste periodo. Possivelmente estes cestos (Figura 10) não teriam sido aqueles utilizados para coleta de sementes de seringueira, dada sua baixa funcionalidade para transporte. Outro tipo de cesto, feito na região de Boim, pode ter sido utilizado: o jamanxim (Figura 11), cesto indígena utilizado nas costas, comumente associado à coleta de castanha-do-pará.

Ainda são grandes os seringais existentes na mata de Boim. Merece destaque uma grande seringueira chamada "Seringueira Mãe". [...] A seringueira mãe fica situada em cima da Serra de Humaitá, aproximadamente $10 \mathrm{~km}$ de Boim. Ela não é a única existente no local. Muitas outras ficam próximas dela formando um seringal. No século passado ela era bastante procurada por causa de sua semente. Sua circunferência é de 7 metros e cinco homens não conseguem abraça-la. Seu potencial de produção é de, aproximadamente, 8 a 12 litros de leite por dia. Quanto aos seringais existentes em Boim, são muitos, tanto que, em 1870, foi grande o fluxo de pessoas para Boim a fim de explorar os seringais. Vieram para Boim familias estrangeiras e nordestinas atrás do precioso produto [...] Era grande a procura do produto, que Boim entrou no cenário nacional e internacional, com especialidades na exportação de sementes para grandes plantios nos países estrangeiros e até mesmo para estados brasileiros. Registra-se que no ano de 1876, foram exportadas de Boim, cerca de setenta mil sementes de seringa. Navios vindos de Belém ficavam no porto de Boim por até três dias, para embarcar as sementes e o precioso "ouro negro". Na época, o transporte da mata para a vila era feito por homens que carregavam nas costas, em jamanxis (COHEN, 2011, p. 86, grifo nosso).
Figura 11 - Cestaria do tipo jamanxim

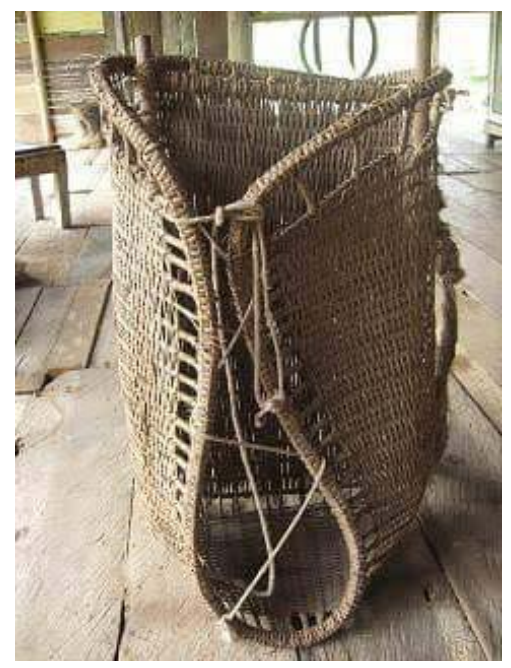

Fonte: Site Patrimônio Cultural da Universidade Fluminense. $^{9}$

\section{Hipótese 10: A "tampa de vidro" que cobria as garrafas sumiu?}

Um novo ingrediente para a analisar esse contexto foi adicionado durante o relato do interlocutor: a referida "tampa de vidro" sumiu! O seringueiro que encontrou as garrafas na área de mata ao retornar para casa, levando aos poucos as garrafas, deixou a tampa de vidro apoiada na árvore e no dia seguinte, ao regressar, não a encontrou mais. Segundo ele foi uma "visagem" que a levou, e que seria resultante de um castigo por ter retirado tais peças do solo. Ao retornar à vila no próximo campo retomarei tal narrativa. Novamente, destaco trecho do livro sobre a história de Boim:

Existem muitas lendas da nossa Vila. Talvez por falta de tempo de pesquisar. não vamos escrever muitas delas, mas essas aqui dão para o amigo leitor achar interessante e talvez, importante para alguma pesquisa ou mesmo para rir um pouco (COHEN, 1985, p. 32).

\section{Considerações finais}

Partindo de prisma relacional sobre fruir com o ambiente, conforme entendido por Tim Ingold

9 Foto meramente ilustrativa. Disponivel em: www.patrimoniocultural.uff.br. Acesso em: 17 jun. 2018. 
(2000), analisarei, por exemplo, a adição de impurezas vegetais ao látex como vestígio da ação humana, que pode ter ocorrido de maneira passiva, à medida que se dava sangria das seringueiras. A dinâmica florestal em plena consonância com os interesses dos seringueiros se encarregava de acrescentar matéria orgânica aos recipientes coletores ao vento esbravejar o adensamento de folhas e galhos secos, assim como restos de insetos e outros materiais. Para averiguar esta pergunta de pesquisa (qual papel da agência do seringueiro?) pretendo seguir além das referências sobre emaranhamentos, o pensamento sobre o não humano de Eduardo Kohn (2013):

Quando focamos apenas nas maneiras pelas quais os pensamentos humanos distintamente se relacionam simbolicamente - que informa a relacionalidade linguistica, cultural e social e como pensamos sobre isso -, perdemos algo da lógica associativa mais ampla dos "pensamentos vivos". O fato de os seres vivos não-humanos serem constitutivamente semióticos faz de si mesmos "selves". Tais seres não-humanos pensam, e seu pensamento é uma forma de associação que também cria relações entre si. Atendendo a essa outra forma de pensamento como uma espécie de relação, sentindo-a até, às vezes, emergindo como seu próprio objeto conceitual e nos abrindo para suas estranhas propriedades (como as possibilidades geradoras inerentes à confusão ou à in-distinção), nos impulsiona a imaginar uma antropologia que pode ir além da diferença como seu componente relacional atômico (KOHN, 2013, p. 224 . tradução nossa). ${ }^{10}$

A ideia aqui é incorporar narrativas não hegemônicas sobre o período da borracha, tanto fazendo usando de uma "imaginação sensória", conforme Bezerra (2011) e trazendo de volta à vida os discursos dos moradores das comunidades sobre suas relações com a cultura material da borracha e seu entorno, assim como, explorar tanto as práticas quanto discursos contemporâneos como elementos da etnoarqueologia, ou para outros autores, arqueologia do presente, ou ainda, arqueologia do/no contemporâneo para adicionar informações sobre técnicas de produção da borracha e toda sua materialidade envolvida.

Nesse sentido, destaco a forma como Tim Ingold (2000; 2012) concebe o processo de fazer coisas em seu aspecto relacional, simétrico e considerando aspectos da agência da floresta, embasado em etnografia de Eduardo Kohn (2013). Para não concluir, estes são apenas alguns apontamentos de pesquisa esboçados até o momento e mais considerações estão em processamento.

\section{Agradecimentos}

O presente trabalho foi realizado com apoio da Coordenação de Aperfeiçoamento de Pessoal de Nivel Superior (CAPES), Código de Financiamento 001, e Erasmus+ Termo de Mobilidade e Treinamento, entre as instituições Linnaeus University (Suécia) e Kew Gardens (Inglaterra). Agradeço aos pesquisadores da Universidade de Brasilia: Floriano Pastore, João Peres, Luis Carlos Pimentel e demais membros do Laboratório de Química e Tecbor - Tecnologia da Borracha para Amazônia - por todo suporte e fazer parte desta equipe; aos pesquisadores Diogo Costa, Agenor Sarraf, Nelson Sanjad, Karl Arenz, Anders Högberg, Cornelius Holtorf, Mark Nesbitt, Federico Fabriani e Katherine Harrington - por todo suporte e contribuições para execução deste projeto e demais desdobramentos. E às comunidades de seringueiros da Amazônia, em especial da Resex Tapajós-Arapiuns e Flona do Tapajós, e demais comunidades associadas às pesquisas do LATEQ/ UnB no Acre e Cotijuba, Pará. 


\section{Referências}

ALVES, Eva da Silva; PINTO, Auxiliadora dos Santos; CAETANO, Renato Fernandes. Memórias de Mulheres Seringueiras na Reserva Extrativista Rio Ouro Preto/ RO: Linguagem, Cultura e Identidade. Amazônica-Revista de Antropologia, [s. l.], v. 10, n. 2, p. 738-761, 2018. https://doi.org/10.18542/amazonica.v10i2.6525.

ARENZ, K. H. Anticaboclismo. Revista de Estudos de Cultura, n. 03, p. 27-38, 2015. https://doi. org/10.32748/revec.voi03.4770.

BEZERRA, Márcia. "As moedas dos indios": um estudo de caso sobre os significados do patrimônio arqueológico para os moradores da Vila de Joanes, itha de Marajó, Brasil. Boletim do Museu Paraense Emilio Goeldi: Ciências Humanas, [s. l.], v. 6, n. 1, p. 57-70, 2011. https://doi.org/10.1590/S198181222011000100005 .

BOAS, F. The mind of primitive man. [S. L.: S. n.]: 1938.

BRITO, Agda Lima. "Eu trabalhei também": as trabalhadoras nos seringais do Amazonas (1940-1950). História \& Parcerias. In: ENCONTRO INTERNACIONAL E ENCONTRO DE HISTÓRIA DA ANPUH-RIO, 18., 2018, Rio de Janeiro. Anais [...]. Rio de Janeiro: [s. n.], 2018.

CARVALHO, Josiane Celerino de. Caracterização morfofuncional e mobilização de reservas primárias durante a germinação e o crescimento inicial de plântulas de Hevea brasiliensis (Willd. Ex Adr de Juss.) Muell. Arg. Dissertação (Mestrado) - INPA, Manaus, 2017.

CASTAÑEDA, Q. The "Ethnographic Turn" in Archaeology. In: ETHNOGRAPHIC ARCHAEOLOGIES. Londres: Altamira Press: Rowman \& Littlefiled Publishers, 2008.

CEMIN, Arneide Bandeira. Denúncias de estupro contra a mulher indigena: Bioética intercultural feminista, saúde coletiva e justiça. Amazônica-Revista de Antropologia, Manaus, v. 8, n. 2, p. 342-370, 2017. https://doi.org/10.18542/amazonica.v8i2.5047.

CESCO, Susana; LIMA, Eli de Fátima Napoleão de. "Terra da Promissão": recolonização e natureza na história amazônica. Territórios e Fronteiras, [s. l.], v. 11, n. 2 , p. 123-151, 2018. https://doi.org/10.22228/rt-f.v11i2.848.

CHAMPNEY, J. W. Travels in the North of Brazil. Acervo Digital da Biblioteca Nacional. [S. L.: S. n.]: 1860. Disponivel em: http://www.bndigital.bn.gov.br//acervo-digital. Acesso em: nov. 2018.

COHEN, Elisio Eden. Vila de Boim (1690-1986) sua história, seu povo. Obras literárias da Prelazia de Santarém. Artesanto Gráfico Tiagão, 1985

COHEN, Elisio Eden. Momentos históricos da Vila de Boim e seu distrito (1690-2011). Prefeitura Municipal de Santarém, 2011.

CONDREAU, Henri. Voyage au Tapajó, 1897.

COSTA, Diogo Menezes. Arqueologia dos africanos escravos e livres na Amazônia. Vestígios: Revista Latinoamericana de Arqueologia Histórica, [s. L.], v. 10, n. 1, jan./ jun. 2016. https://doi.org/10.31239/vtg.v10i1.10568.
DEETZ, J. In small Things forgotten: an archaeology of early american life. New York: Anchor: Doubleday, 1996.

GANE, N.; HARAWAY, D. Se nós nunca fomos humanos, o que fazer? Gane \& Haraway-Interview with Donna Haraway. Ponto Urbe: Revista do núcleo de antropologia urbana da USP, n. 6, 2010.

HARAWAY, D. Anthropocene, capitalocene, plantationocene, chthulucene: Making kin. Environmental humanities, [s. l.], v. 6, n. 1, p. 159-165, 2015. https:// doi.org/10.1215/22011919-3615934.

HILLS, D. A. Heat transfer and vulcanisation of rubber. [S. l.]: Elsevier Publishing Company, 1971.

INGOLD, T. The perception of the environment: essays on livelihood, dwelling and skill. Londres: Routledge, 2000.

INGOLD, T. Los Materiales contra la materialidad. Papeles de Trabajo, Revista Electrónica del Instituto de Altos Estudios Sociales de la Universidad Nacional de San Martin, [s. l.], v. 7. n. 11, 2013.

JACKSON, Joe. O ladrão no fim do mundo: como um inglês roubou 70 mil sementes de seringueira e acabou com o monopólio do Brasil sobre a borracha. [S. l.]: Editora Objetiva, 2011

KOHN, E. How forests think: Toward an anthropology beyond the human. Berkeley: University of California Press, 2013. https://doi.org/10.1525/california/9780520276109.001.0001.

LAGE, Mônica Maria Lopes. Mulher e seringal: um olhar sobre as mulheres nos seringais do Amazonas (1880-1920). Dissertação (Mestrado em História) UFAM, Manaus, 2010

LATOUR, Bruno. Jamais fomos modernos. [S. l.]: Editora 34, 1994

LINDSEY, Bill. Historic Glass Bottle Identification \& Information Website. [S. l.: S. n.]: 2018. Disponivel em: https://sha.org/bottle/. Acesso em: 13 abr. 2018.

MARTIUS, Karl von. Beiträge zur Ethnographie und Sprachenkunde Amerikas zumal Brasiliens. Die ehemalige Verbreitung und die muthmasslichen Wanderungen der Tupis. In: BIBLIOTECA DIGITAL CURT NIMUENDAJU. [S. l.: s. n.]: c1867.

MCGUIRE, R. H.Archaeology as Political Action. Berkeley: University of California, 2008.

MILLER, G. L. Classification and economic scaling of 19th century ceramics. Historical Archaeology, v. 14, n 1, p.1-40, 1980. https://doi.org/10.1007/BF03373454.

MUNIZ, Tiago Silva Alves; GOMES, Denise Maria Cavalcante. Identidades materializadas na Amazônia Colonial: a cerâmica dos séculos XVIII e XIX do sítio Aldeia, Santarém, PA. Vestigios: Revista Latino-Americana de Arqueologia Histórica. v. 11, n. 2, p. 52-76, 2017. https://doi.org/10.31239/vtg.v11i2.10445.

MUNIZ, Tiago Silva Alves. Materiais e fluxos na Amazônia Colonial: evidências da presença de africanos escravizados no sítio Aldeia, Santarém, Pará. Revista de Arqueologia, [s. l.], v. 32, n. 2, p. 16-35, dez. 2019. https://doi.org/10.24885/sab.v32i2.690. 
ODELL, John. Big Bottles, Big History: Demi-Johns and Carboys. Antique Bottle \& Glass Collector, v. 25, n 7. p. 28-33, 2008. Disponivel em: http://www.bottlebooks.com/demijohn/big_bottles_big_history_demijohn.htm.

OLIVEIRA FILHO, João Pacheco de. O caboclo e o brabo: notas sobre duas modalidades de força de trabalho na expansão da fronteira amazônica do século XIX. In: SILVEIRA, E. (org.) Encontros com a civilização brasileira. Rio de Janeiro: Civilização Brasileira, 1979. p.101-140.

OLSEN, B. In defense of things: archaeology and the ontology of objects. [S. L.]: Rowman Altamira, 2010.

PASTORE JR, F. Tratamento do látex de borracha natural com tanino vegetal. Tese (Doutorado) - Universidade de Brasilia, Brasília, DF, 2017.

REZENDE. Vinícius de. "Tinha que ser macho": as condições de trabalho e as disputas em torno do adicional de insalubridade no setor coureiro-calçadista de Franca-SP (1950-1980). In: SIMPÓSIO NACIONAL DE HISTÓRIA, 27., 2013, Natal. Anais [...]. Natal: ANPUH, 2013.

ROOSEVELT, Theodore. Through the Brazilian Wilderness. New York: Scribner Print, 1914.

SHANKS, M.; TILLEY, C.Y. Re-constructing archaeology: theory and practice. [S. l.]: Press Syndicate of the University of Cambridge, 1987.

SOUZA, Rafael de Abreu. Grés, vinho e imigração: arqueologia de uma produção vitivinícola, São Paulo, 1920-1950. Boletim do Museu Paraense Emilio Goeldi: Ciências Humanas, [s. l.], 2013. https://doi. org/10.1590/S1981-81222013000100003.

SYMANSKI, Luis Cláudio Pereira; GOMES, Denise Maria Cavalcante. Mundos mesclados, espaços segregados: cultura material, mestiçagem e segmentação no sítio Aldeia, Santarém, PA. Anais do Museu Paulista, v. 20, n. 2, p. 53-90, 2012. https://doi. org/10.1590/S0101-47142012000200003.

SYMANSKI, Luis Cláudio Pereira; GOMES, Denise Maria Cavalcante. Material Culture, Mestizage, and Social Segmentation in Santarém, Northern Brazil. In: FUNARI, Pedro Paulo A.; SENATORE, Maria Ximena (ed.). Archaeology of Culture Contact and Colonialism in Spanish and Portuguese America. [S. L.]: Springer International Publishing, 2015. p. 199-217. https://doi. org/10.1007/978-3-319-08069-7_11.

TAVARES, Rufno Luis. O Rio Tapajoz. Rio de janeiro: Typhographia Nacional, 1876.

ULE, Ernst. Museu Paraense Emilio Goeldi Arquivo Guilherme de la Penh. Coleção fotográfica 1908-1909.

VALE, Ana. A Arqueologia e as Coisas. A disciplina e as correntes pós-humanistas. Almadam, [s. l.], 2015.

WEINSTEIN, Barbara. The Amazon rubber boom, 1850-1920. [S. l.]: Stanford University Press, 1983.

WOLFF, C. S. Mulheres da Floresta: uma História do Alto Juruá, Acre (1890-1945). São Paulo: HUCITEC, 1999.
WYNAND FOCKINK. Wynand Fockink Website. IS. l.: s. n.]: [2000?]. Disponivel em: http://wynand-fockink. nl/. Acesso em: 13 abr. 2018.

\section{Tiago Silva Alves Muniz}

Arqueólogo, pesquisador visitante no Departamento de Ciências Culturais, Linnaeus University (Kalmar, Suécia); doutorando em Antropologia (Arqueologia) pela Universidade Federal do Pará (UFPA, Belém, PA, Brasil).

\section{Endereço para correspondência:}

Tiago Silva Alves Muniz

Universidade Federal do Pará

R. Augusto Corrêa, 01

Guamá, 66075-110

Belém, PA, Brasil 